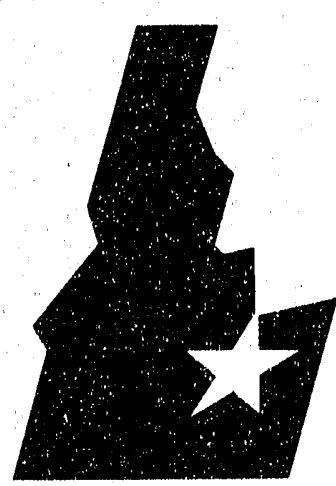

Idaho National

\section{Engineering}

Laboratory

Managed

by the U.S.

Department

of Energy $i$

\section{MAR 20190}

PRODUCT ASSURANCE PLANNING IN AN ENVIRONMENT OF INCREASED NEED FOR ACCOUNTABILITY
V. Esparza
C. Casey

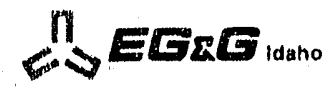

Work performed under DOE Contract No. DE-AC07-761D01570 


\title{
PRODUCT ASSURANCE PLANNING IN AN ENVIRONMENT \\ OF INCREASED NEED FOR ACCOUNTABILITY
}

\author{
V. Esparza and C. Casey
}

Published October 1991

EG\&G Idaho, Inc.

Idaho Falls, Idaho 83415

\author{
Prepared for the \\ U. S. Department of Ene:gy \\ Idaho Operations office \\ Under DOE Contract no. DE-AC07-701D01570
}


Projects producing data are too often providing a product that is neither defensible nor usable. Instead of planning for data of known and required quality, managers are too often asking for (and getting) the wrong thing. The problem is a lack of correct planning strategy. A planning strategy to produce usable, defensible data requires communication from the customer to top-level management and from top-level management to the project leader, who must then communicate with the technical experts who will run the project. EPA requires that data quality objectives (DQOS) be derived for RI/FS projects. The DQO process is a top-down $\mathrm{planning}$ process that requires two-way communication; some organizations do not have structures suited for implementing DQOS as mandated by EPA.

This paper discusses specific tools for imposing structure that will make the DQO process easier to follow for many organizations. The tools include a steering committee, a test design team, and Quality Function Deployment (QFD) matrices. The steering committee is a strong technical forum that can develop technical issues systematically and break down technical issues into manageable pieces that can be stated as test objectives. The test design team plans each test, systematically designs the test matrix, and guides the completion of test documentation that will be used to defend the data collected. QFD matrices are used as tools by both steering committee and test design team as a highly structured, systematic means of relating top-level (customer) requirements to data quality needs and measurement system design.

\section{DISCLAIMER}

This report was prepared as an account of work sponsored by an agency of the United States Government. Neither the United States Government nor any agency thereof, nor any of their employees, makes any warranty, express or implied, or assumes any legal liability or responsibility for the accuracy, completeness, or usefulness of any information, apparatus, product, or process disclosed, or represents that its use would not infringe privately owned rights. Referprocess disclosed, or represin to any specific commercial product, process, or service by trade name, trademark, manufacturer, or otherwise does not necessarily constitute or imply its endorsement, recommendation, or favoring by the United States Government or any agency thereof. The views and opinions of authors expressed herein do not necessarily state or reflect those of the United States Government or any agency thereof. 


\section{ACKNOWLEDGMENTS}

The authors would like to thank A. J. Nelson for information on the Analytic Hierarchy Process and M. D. Herd for help with the test design team section. C. J. Graden, R. N. Hunt, and P. J. Reep offered many valuable suggestions. 


\section{CONTENTS}

Introduction ........................... 1

Data Quality Planning . . . . . . . . . . . . . . . 3

Quality Function Deployment (QFD) Matrices . . . . . . . . . . . . 4

The Steering Committee . . . . . . . . . . . . . . . . . 6

Steering Committee QFD Matrix . . . . . . . . . . . . . . . . . 7

Test Design Team . . . . . . . . . . . . . . . . . . 9

Test Design Team QFD Matrices . . . . . . . . . . . . . . 12

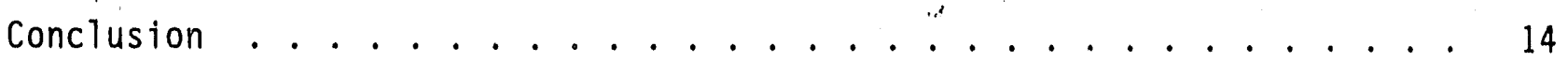

References ........................ . . 15

APPENDIX A: DQO PROCESS . . . . . . . . . . . . . . . . 16

APPENDIX B: EXAMPLE PROBLEM STATEMENT . . . . . . . . . . . . . . . . 18 


\section{PRODUCT ASSURANCE PLANNING IN AN ENVIRONMENT \\ OF INCREASED NEED FOR ACCOUNTABILITY}

\section{Introduction}

New Department of Energy (DOE) regulations governing contractor accountability may decrease contractors' award fees: Costs found by DOE to be avoidable, such as costs for inadequate or failed projects, will not be paid by DOE, particularly if contractor negligence can be shown. Managers in some cases could be held legally liable for money spent that does not produce tangible and usable results. Even if DOE had not made these regulations, at the least, failed projects have uselessly spent money that could have been used elsewhere.

At federal facilities where contractors are planning to perform hazardous waste cleanups, the work is governed by Environmental Protection Agency (EPA) regulations. The EPA has prosecuted both companies and individuals who, through negligence, willful or not, have violated regulations. Lack of systematic planning for projects related to hazardous waste cleanups can be seen as negligence on the part of those responsible for the planning.

Complex projects may often be difficult to plan. If planning is not done extensively enough or in the correct fashion, the end products may not fill the initial requirements. Projects producing data may produce a product that is neither defensible nor useable. Managers of these projects are often unable to account for how the project went wrong. How can this happen? Some of the most bright and talented people in the country work on these projects. Lack of qualified personnel is rarely the problem.

Instead of planning for data of known and required quality, managers often ask for (and get) the wrong thing. Many projects performed by federal government contractors have no product other than data; if the data are unusable, the project actually produces nothing. The results of continuing this way are potentially disastrous. 
A planning strategy to produce useable, defensibl: data requires communication from the customer to top-level management and fiom top-level management to the project leader, who must then communicate with the technical experts who will run the project. Lack of communication at any level will stall the planning process. Communication may be verbal, but in a11. cases must then be documented in writing. Undocumented verbal communications can too easily be misremembered, misinterpreted, ignored, or forgotten. Written communications will also make the project more auditable, as the thought process leading to the final product will be documented, and managers will be more accountable.

In many cases the most apparent customer is not the one who should be defining the requirements for the project. Often the person or agency who supplies the funding for a data-gathering project is not the one who will ultimately use the data. The data-user is the person who must set the requirements for the data, including stating the problem the data are meant to address. The sponsor of the project may often provide no more than money and some managerial expertise. It may be difficult to discover who is the real customer, the end-user of the data, but in all cases the data are much less likely to suit the real requirements unless the end-user is treated as the customer.

Several DOE sites have been placed on the National Priority List (NPL) and are preparing to undergo remedial investigation/feasibility studies (RI/FS). The objective of a RI/FS is to gather data to assess the feasibility of a remediation technology for a waste site. In some cases, a need may be found for development of innovative remediation technology. Technologies not previously used for the type of site under study may be adaptable to it. To begin with, no possibility that may work is excluded. Later, an initial feasibility screen is applied to determine which alternatives are worthy of further development. Thus some projects related to a RI/FS may be technology development or treatability study projects.

Environmental engineering systems require strict quality assurance (QA) to assure safe and effective operation. Only minimal EPA guidance on QA for engineering systems is available that has limited applicability to technology development. Inadequate design, construction, or operation could pose health 
and environmental concerns and impact worker safety. The EPA has suggested that for technology development projects, QA requirements of NQA-1 ${ }^{1}$ be adhered to. ${ }^{2}$ Data quality planning should conform to the DQO process mandated by EPA.

\section{Data Quality Planning}

Many programs at DOE sites have at least one thing in common: a customer is seeking information in the form of data to make decisions or evaluate performance of a process. The desired data quality is achieved through planning. Lack of planning can lead to data whose quality are below the level needed, so that decisions made on the basis of the data may be incorrect (or worse). The need to do investigations cheaper, better, and faster is often in conflict with requirements that data be traceable and defensible. This conflict can overwhelm an investigation so that none of the goals are met. Data of known quality will result in decisions based on the data being of known quality. Both money and time will be saved, because data will be collected right the first time.

To help avoid these problems, a data quality planning process is required for a data collection program. For data-producing projects, F.PA has defined the data quality objective (DQO) process, a systematic planning process intended to produce data of known quality for decision-making in superfund sleanups. ${ }^{3}$ The derivation of DQOS is a vital step in data planning. The DQO process is a three-phase iterative planning process by which a decision to be made or the goals of a data gathering project are stated, and uncertainties that can be allowed in the context of the decision or objective are stated.

A complete description of the DQO process, as developed by EPA, is given in Appendix A. The EPA's method of deriving DQOS is based on its own organizational structure. Other organizations may have to modify the process to suit their own structures. This paper describes some modifications that will work in many situations for a variety of types of projects. Although the following refers to a planning process for data-gathering projects, the same process could easily be modified to use for any type of project planning. The use of three 1.001s is suggested for planning: Quality Function Deployment (QFD) matrices, a steering committee, and a test design team. 
The steering committee facilitates the DQOs through Level 1 and Level 2 of the EPA-described process. The test design team takes the place of the technical specialists who, in the EPA process, chiefly do Level 3 DQOS, also helping with the Level 2 part of the process where appropriate. Thus, the use of these teams is a way of imposing an organizational structure that will correspond to the structure used by EPA to derive DQOS. Using QFD matrices for planning imposes further structure on the process.

The DQO process is a top-down planning process, but, more important, it is a two-way (or a11-way) communication process. One-way communication will not meet with success. Communication should be documented in writing, through memos, letters, or transcripts of meetings. Such records, kept in project files, make the program more auditable and managers more accountable.

A DQO communications matrix has been developed to depict what communications are needed to develop complete DQOs; it is illustrated in Figure 1 . The columns represent required parts of the process; the rows represent people whose participation is required in the process. A double-headed arrow from one row to another in any column means that people in those raws should communicate to complete that part of the $D Q O$ process. A single-headed arrow means only transmission of information from one row to another.

\section{Quality Function Deployment (QFD) Matrices}

The QFD process has been described a number of times. ${ }^{4}$ In short, it is a means of using matrices to relate one set of things, such as customer requirements, to another, such as product design requirements. QFD usually invnives construction of a "house of quality", several attached matrices, with an interaction matrix on top, which is shaped rather like a house. Matrices may be cascaded so that ranges call be related to other ranges downstream. The DQ0 process involves several points at which one item is related to another. Initial requirements are translated into overall acceptable uncertainty. Overall uncertainty is translated to uncertainties allowable for each type of data. Those uncertainties are related to quality and quantity of data to be gathered, which is then related to components of the measurement system that 


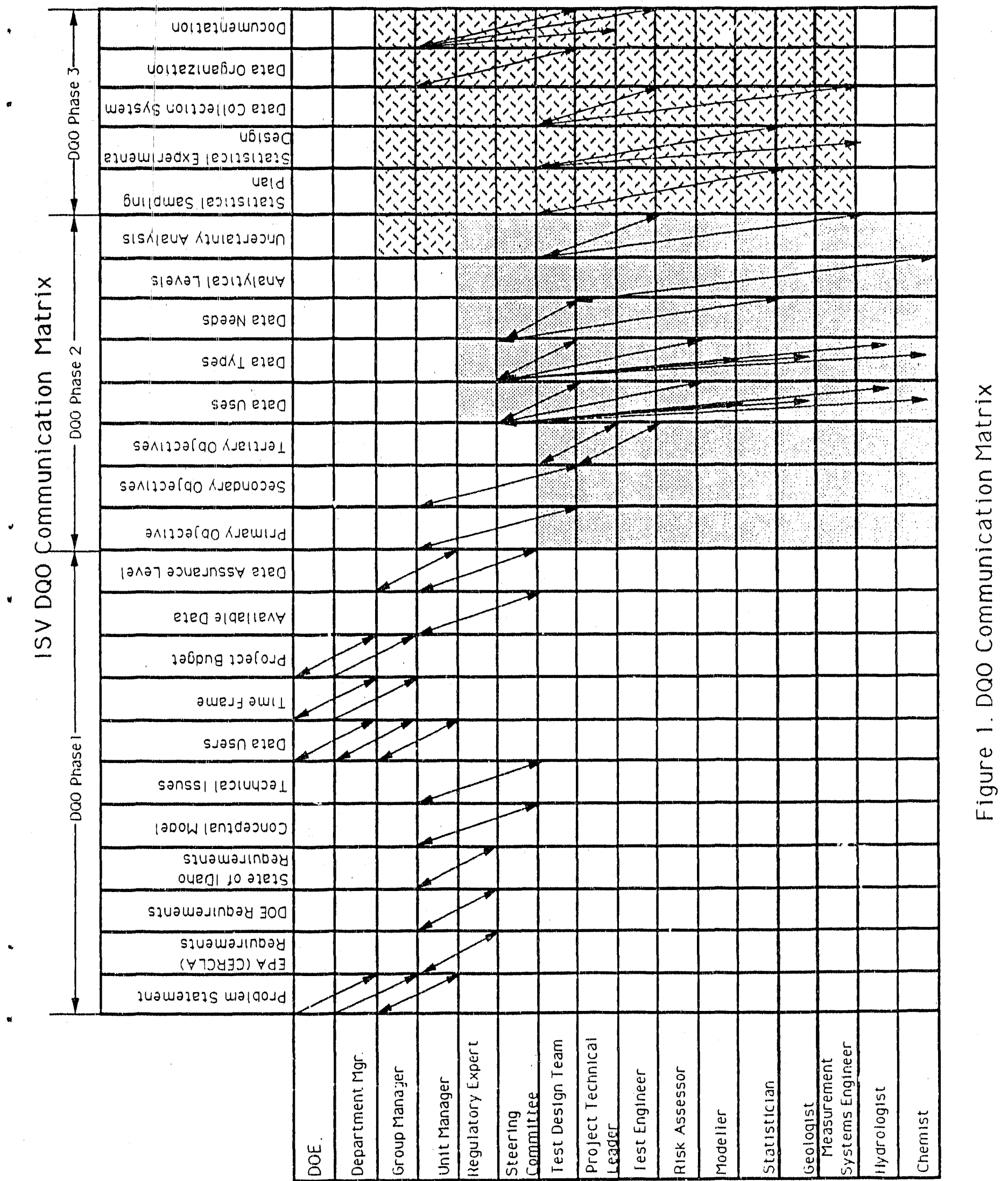


will gather the data. Matrices can be used for each of these conversions. Further, matrices can be used in the complete design of a measurement system, where data quality requirements are translated to system components. Specific uses of QFD will be discussed further below.

\section{The Steering Committee}

A steering committee is needed to provide a strang technical forum, to develop technical issues systematically, and to break down technical issues into manageable pieces that can be stated as test objectives. A multi-discipline team is needed to develop the thought process and recommend how best to address each issue. Selection of members for the team is crucial to the success of an experiment or investigation. The Steering Committee's mission is to:

- Facilitate interaction among levels uf management for Level 1 and 2 of the DQOs by creating interactive talks through meetings and drafting formal action letters for management signature and release

- Assist the customer in defining the problem

- Develop a conceptual model that describes the problem

- Define and prioritize technical issues associated with the probiem and the proposed experiment

- Define requirements for resolution (closure) of technical issues

- Develop "roadmaps", guidelines for obtaining closure of issues

The individuals who make up the steering committee are selected for their understanding of the political climate and technical implications of the project. They conduct discussions among top-level decisions-makers (the customers) and those who will guide the project. They must be senior-level people who have the required experience and education. Some disciplines that might be included on a steering committee for a RI/FS could be: 


\author{
Statistician \\ Chemist \\ Modeler \\ Hydrologist/Geologist \\ Regulatory expert \\ Experiment Planning expert \\ Chairperson
}

The chairperson should be an individual with strong leadership skills, who is trained in and can facilitate QFD.

The steering committee must be independent from management biases. It acts as a communication interface for a11 levels of management involved in the project and advises them in top-level planning. It is the hub of a wheel that organizes the spokes, communications routes, to management. Its most important role is to assist management in drafting written communication in which specific requirements are spelled out for the data planning process.

\title{
Steering Committee QFD Matrix
}

The purpose of the steering committee is to focus and control the planning of experiments and investigations, based on technical priorities and issues. It must consider ten key elements in data quality planning:

1. Problem Statement

2. Research Goal

3. Risk issues

4. Technical issues

5. Prioritization of issues

6. Regulatory requirements

7. Quality assurance targets

8. Milestones

9. Budget

10. Schedule 
The QFD matrices will be used to derive requirements for the project; they are part of level one of the DQO process. Inclusion of QFD matrices in quality planning can ensure that all necessary elements are addressed and that customer requirements are met. QFD matrices can promote communication and interaction among steering conmittee members and others with whom they must interact.

The problem statement is the most critical of the ten elements, since no planning can be done without it. Communication of the problem statement from the customer to the project manager and the steering committee is crucial in finding what solutions are available and how long a time is needed to resolve the problem. The customer may need help to clarify the full problem statement for others' understanding. The problem statement must be in writing so that it may be referred to for later phases of planning. The statement must contain enough details and background to provide sufficient guidance to the project manager and the steering committee. Many projects fail because the problem has been defined too broadly or sufficient detail has not been given. An example of a problem statement that might be used for a RI/FS is given in Appendix B.

Because there is a difference between a research project, in which an answer is sought to a particular question, and a development project, in which knowledge is gained towards developmen $\imath$ of a new product, planning and specifications for each will be different. To focus planning, the type of project must be understood. Projects conducted for a RI/FS are typically research projects although, in some cases, remedial technology development projects will also be needed. A goal must be established for the project before research can be initiated. The research goal is a hypothesis statement that may be proved or disproved, such as, "In situ vitrification is a viable remedy for a buried waste site."

Risk issues are hazards that must be understood to ensure public safety. These are also written as hypothesis statements. For example, "Airborne emissions are within acceptable limits." A technical issue is any phenomenon, process, or condition that must be understood and quantified to ensure that safety, feasibility, environmental compliance, and product quality of the prcposed appiication are not compromised. A technical issue is developed by 
examining inputs and outputs to the conceptual model that may be pathways by which worker safety or environmental compliance could be compromised.

A procedure used for establishing priorities among the issues is the Analytic Hierarchy Process $(A H P)^{5}$, a systematic process for expressing and documenting a preference (priority) structure. The method uses a pairwise relative importance assessment procedure that leads to final preference weights for a set of alternative choices. The typical decision problem may be expressed as a hierarchical decision structure, with the goal of making an optimal decision as the top level of the hierarchy. The major criteria form the second level. Sub-criteria may be introduced on lower levels of the hierarchy, if necessary. The bottom level, usually the third or fourth, consists of alternative choices open to the decision-maker. The AHP process is well documented in the literature.

The accuracy of a test or experiment is often part of the test requirements. It can be defined by a pretest uncertainty analysis, which allows for corrective action on a measurement system before the test to improve uncertainties vhen they will be greater than acceptable. The pretest analysis is based on data and information that exist before the test, such as calibration histories, previous tests with similar instrumentation, prior measurement uncertainty analysis, and expert opinions. For complex tests theie are often alternatives to evaluate, such as different designs, instrumentation layouts, alternate calculation procedures, and concomitant variables. Pretest analysis will identify the most accurate test method.

An example of the steering committee matrix is shown in Figure 2.

\section{Test Design Team}

The test design team plans each test, designs the test matrix to ensure test planning is done in a systematic manner, and guides tre completion of test documentation that will be used to defend the data collected. These functions are chiefly part of Level 3 DQOS, as defined by EPA and described in Appendix $A$. 


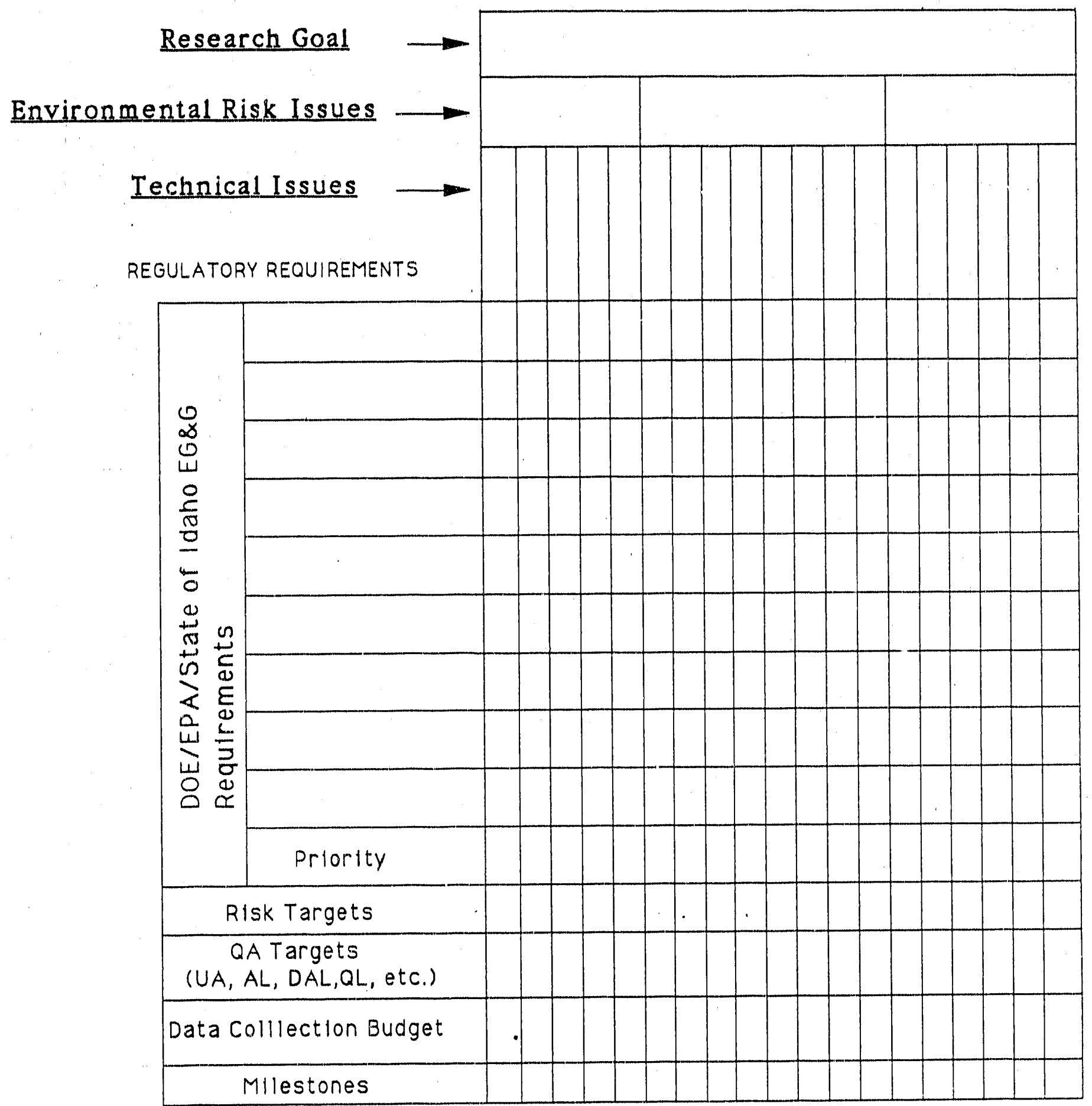

[D Indicates strong

Relationship

[a] Indicates Moderate

Relationship

Note: $U A=U n c e r t a i n t y$ Analysis

$A L=$ Analytical Levels

Indicates No

$D A L=$ Data Assurance Levels

$Q L=$ Quallty Levels

Relationship

Figure 2. Steering Committee QFD Matrix 
The team members should be experienced in many types of test configurations that will be relevant to the project. Experience in measurement systems is crucial so that the measurement systems can be designed to obtain the needed data. Test planning should be comprehensive and detailed so that the uncertainty of the data is minimized.

The test design team will provide continuity from one test to another, ensure that the overall test saquence remains focused on the objectives, and guarantee that a 11 customer requirements are met. It will implement DQO methodology to determine quality objectives and accuracy of measurements to satisfy test objectives. The test design team's mission is to:

- Design the tests

- Be an interface among the steering committee, project manager, and operations personne 1

- Use QFD matrices to develop the rationale for the test design

- Assist management in drafting action letters for accountability in complying with the DQO process.

- Consult with the project manager on necessary tasks

- Assist in developing short and long range goals for the experiment.

The test design team will prepare specific plans for each test set. The process for designing tests requires consideration of:

Utilization of models for predicting response

Selection of top-priority technical issues and variables to screen

Statistical Design of Experiments (SDE) test set design

Selection of outputs to be measured for:

Analytical data and support assessment 
Data for safety and health risk assessment

Data for engineering equipment design

Product quality data

Data for process control

Data for model validation and verification

Post-test analysis

Data interpretation

Interim report issued

Final technical report issues

Further testing if needed

\section{Test Design Team QFD Matrices}

QFD matrices will be used to design requirements into the test $p 1$ an as part of the DQO process. The matrices organize objectives derived by the steering committee and relate them to statistical design of experiments, data storage, and other low-level requirements. The team will use matrices to ensure that all needed data are obtained and that all customer needs are satisfied.

The planning matrix transforms the top priority technical issue into primary, secondary, and tertiary objectives; designs laboratory and field tests, and ensures correct data are collected to support test objectives. The test design team must consider several key elements in the planning matrix, including

1. Primary objectives

2. Secondary objectives

3. Tertiary objectives

4. Test controlling characteristics

5. Quality assurance targets

6. Milestones

7. Product

8. Secondary product

9. Tertiary product

10. Quality control items 
Figure 3 illustrates the matrix that would result.

Each objective developed by the steering committee is transformed by the test design team to a workable, specific primary objective for each test series. The primary objective is broken down into secondary objectives to add more precision. Then each secondary objective is decomposed into tertiary components that will guide operations personnel and test engineers. Tertiary objectives are the specifics necessary to direct test activities.

The test controlling characteristics are statements that dictate the type of analysis, data validation, and so on, that will be used to control output characteristics of the data collected. The QA targets are values that are used to demonstrate quality compliance with requirements. Many types of tarcet values are possible in a test program, such as measurement uncertainty targets, environmental risk targets, analytical levels, and data assurance levels.

Conclusion

For systematic planning of data quality, DQOS are mandated by EPA for remedial investigations. DQOs are also useful for any project whose end product is data. For organizations that do not have the structure described by EPA, the necessary structure may be imposed by use of the tools described above. A steering committee can facilitate the derivation of level one and two DQOS. The test design team can take the process further and design level three DQOs into the test planning process. QFD matrices are a highly structured, systematic means of relating top-level requirements to data quality needs and measurement system design. These tools are flexible enough to be used for planning all types of projects, large and sma11, or with differing quality requirements.

In an environment of increased exposure to liability and need for accountability, managers need to be assured that the quality of their product (whether data or not) is maximized and known and that the uncertainty of data is minimized so that the uncertainty of decisions made using the data is miminized. The three tools presented here are valuable when used in planning for data 


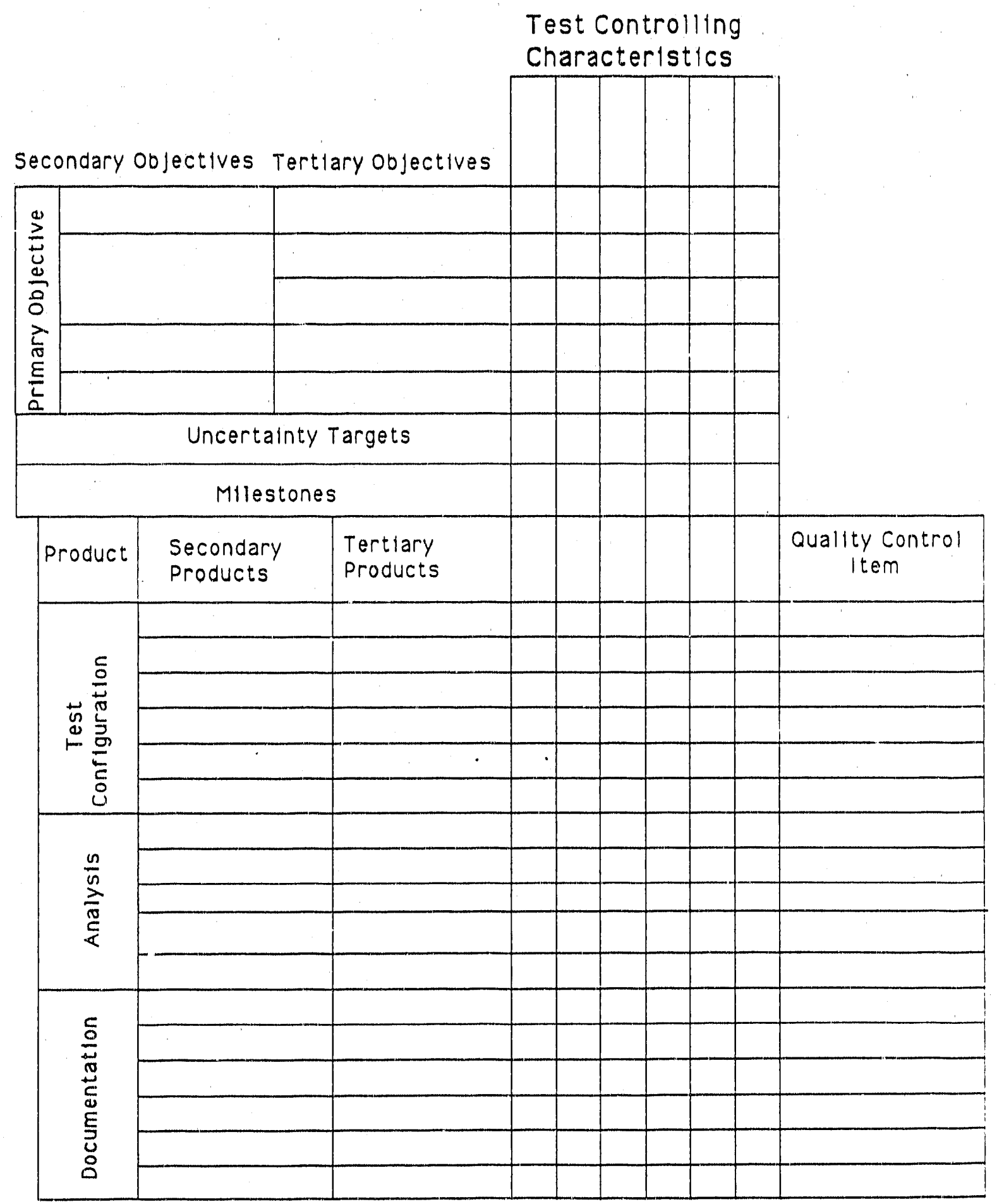

Figure 3. Test Design Team QFD Matrix 
quality. The beneficial results of using the structured approach presented here include:

- Increased technical and legal defensibility of data

- Increased managerial accountability

- Aid in minimizing such avoidable costs as fines and penalties and the costs of litigation

- Assurance of data quality

- Minimization of impacts to contractor award fees

- Data-collecting projects are done right the first time 


\section{References}

1. ASME NQA-1, Quality Assurance Requirements for Nuclear Facility Applications, 1989.

2. Johnson, G. L. and Wentworth, N. W., "A National QA Standard for Environmental Programs for Hazardous Waste Management Activities", Proceedings, Seventh Annual Waste Testing and Quality Assurance Symposium, July, 1991.

3. U. S. Environmental Protection Agency, Data Quality Objectives for Remedial Response Activities, EPA/540/G-87/003, PB88-131370, March, 1987.

4. Sullivan, L. P., "Quality Function Deployment", Quality Progress, June, 1986, p. 39.

Hauser, John R. and Clausing, Don, "The House of Quality", Harvard Business Review, May-June, 1988, p. 63.

5. Saaty, Thomas L., The Analytic Hierarchy'Process, New York, McGraw-Hi11, 1980. 


\section{APPENDIX A: DQO PROCESS}

The first phase of the DQO process requires input from the program manager, who consults with project managers and sentor technical staff. Management is defined as the person or persons who w111 use the data to answer a question or make a decision. The first step is to state what questions are to be answered by the data, what decisions are to be made based on $i t$, or what are the objectives of the test or experiment. The budget available is also defined.

The next step is to define what information is reeded to answer the question. Then any existing data can be analyzed to learn if it will answer the question or make the decision possible. If it is decided that new data will be needed, then a process model of the situation should be developed, and the results of incorrect data clearly stated in an if...then format.

This first phase of the process may be achieved in a variety of ways, such as through memos, letters, or meetings, but the purpose is for management to communicate with the senior technical staff what decision is to be made, what information is needed, and the effects of an incorrect decision.

The second phase of the DQO process is done by project managers and senior technical staff, using the information communicated to them by program management. . If the question or decision consists of more than one question, the subquestions are identified.

The types of data needed to answer the questions or make the decision are then decided, as well as the use of each data type, relating the use to the basic question or decision. At this time the desired data assurance level (data assurance levels are discussed further below) of the data is decided, based on the importance of the deciston and the consequences of making an incorrect decision, and the quantity of data needed for the chosen quality level is specified.

A decision is made about the level of uncertainty that can be tolerated, based on customer requirements. Deciding the level of uncertainty allowable in the data may be an complex process, and should be done with the help of an 
authority on uncertainties. The total uncertainty of the data gathering process must be analyzed, including sampling errors as well as analytical errors, and the procedures for computing the total uncertainty must be defined.

During the second phase, one of three data assurance levels is chosen:

Leve1 1: Complete data planning process, combined with documentation governed by a Configuration Management Plan, and independent review.

Level 2: Complete data planning process, with documentation organized under a Quality Program Plan, with program/project review.

Level 3: Data planning process less rigorous; however, the main steps outlined here should be followed; technical investigation control of documentation and peer review. This level allows for scoping data for which quality requirements are not as rigorous.

A further part of phase 2 should be a statement of the place and time of interest. Understanding the boundaries of the problem may help to eliminate the collection of unnecessary data that do not apply to the question or decision.

In the third phase of the DQO process, the data collection program is designed by the technical staff, using as input the output of phases 1 and 2 . Planning the data collection program includes designing the measurement system and a sampling strategy and deciding what documentation will be used to support the data. In phases 1 and 2 the am:ant of total uncertainty that can be tolerated in the program was decided; this is translated into the total acceptable uncertainty in the data. The design should be tailored to achieve a total uncertainty that meets program requirements. 
NOTE: This memo is a simulation; it has never been sent or received by anyone. Jan 1,1990

TO: Contractor

FROM: Sponsor

SUBJECT: $\quad X Y Z$ Landfi11 problem statement

The XYZ Landfill has been used for the disposal of hazardous and radioactive (mixed) wastes, resulting in the contamination of the underlying aquifer. Twelve purgeable organic compounds were detected in samples taken from the aquifer in 1987; only carbon tetrachloride $\left(\mathrm{CCl}_{4}\right)$ was detected above the Federal Primary Drinking Water Standard Maximum Contaminant Level (MCL) of $5 \mu \mathrm{g} / \mathrm{L}$; its concentration was $6.6 \mathrm{\mu g} / \mathrm{L}$. In addition, tetrachloroethylene (PCE) and trichlorethylene (TCE) were detected above their Maximum Contaminant Level Goals (MCLGs), which are zero for these compounds and $\mathrm{CCl}_{4}$. The aquifer alsc contains low levels of radionuclides, including tritium and ${ }^{90} \mathrm{Sr}$. The area surrounding the landfill and the sedimentary interbeds below the buried waste are also contaminated. A soil gas survey conducted in 1987 detected $\mathrm{CCl}_{4}, \mathrm{PCE}, 1,1,1$ trichloroethane, and TCE above their method detection/quantitation limits. The highest concentrations of carbon tetrachloride, PCE, and TCE were found above Pit $A$. Volatile organic contaminants have been found in the sedimentary interbed below Pit $A$, when borehole drilling equipment exposed some of the interbed during drilling activities in 1987. Migration of radionuclides from the buried waste at the landf 111 has been monitored for several years, showing that plutonium, ${ }^{137} \mathrm{Cs}$, and ${ }^{90} \mathrm{Sr}$ have migrated to the sedimentary interbeds.

Concern has been expressed that the aquifer could become contaminated at levels hazardous to human health. It supplies drinking water for a large population, though not close to the contaminated site, so the current low contamination levels do not endanger any populations except possibly on-site workers. 
A decision has been made to initiate a RI/FS. Because the configurations and types of wastes at the landfill differ from previous sites remediated under CERCLA, it is expected that remedial technology must be specifically developed for this site. The goal for the Remedial Design (RD) should be to ensure that workers and the public are not endangered by a contaminated aquifer. Exact risk levels to be allowed have not yet been decided. 
